\title{
Modification of Bitumen Properties Using Waste Polymer in Context of Bangladesh
}

\author{
Mohammad Mohayminul Islam ${ }^{1, *}$, Mosammat Shamima Shirin ${ }^{2}$, Tausif Rahman Tonoy ${ }^{2}$, \\ Sanzit Ahmed Sweet ${ }^{2}$ \\ ${ }^{1}$ Department of Civil Engineering, Rajshahi University of Engineering and Technology, Rajshahi, Bangladesh \\ ${ }^{2}$ Department of Civil Engineering, Bangladesh Army University of Engineering \& Technology, Natore, Bangladesh
}

\section{Email address:}

mohayminul.islam37@gmail.com (M. M. Islam), shamima091@yahoo.com (M. S. Shirin), tausif.rahman15h@gmail.com (T. R. Tonoy), sasweet87@gmail.com (S. A. Sweet)

${ }^{*}$ Corresponding author

\section{To cite this article:}

Mohammad Mohayminul Islam, Mosammat Shamima Shirin, Tausif Rahman Tonoy, Sanzit Ahmed Sweet. Modification of Bitumen Properties Using Waste Polymer in Context of Bangladesh. International Journal of Mineral Processing and Extractive Metallurgy.

Vol. 6, No. 1, 2021, pp. 6-11. doi: 10.11648/j.ijmpem.20210601.12

Received: March 28, 2021; Accepted: April 12, 2021; Published: April 26, 2021

\begin{abstract}
Proper disposal of plastics and its derivatives is one of the biggest challenges all over the globe. Due to the improper management of plastic product environment is being polluted. Plastic waste generation and plastic waste-based pollution in Bangladesh is leaping at a high pace. Among numerous ways of disposal of waste plastics, one can be using it in flexible pavement construction. According to the Bangladesh Waste Database 2014, Dhaka city alone produces 25.44\% (5,925.51 tons/ day) of waste, of which $8.45 \%$ is plastic. In the construction of bituminous pavement, plastics, as well as construction debris, are being used in the form of aggregate and filler materials popularly. This study focusses on the improvement of properties of bitumen by blending it with LDPE (Low-density polyethylene) and PP (Polypropylene) at a different proportion. Three cases were considered in the study for plastic waste addition, Case-01:- only LDPE; Case-02:- LDPE: PP=3:1; Case-03:- LDPE: $\mathrm{PP}=1: 1$. For each case, $3 \%, 6 \%, 9 \%, 12 \%$, and $15 \%$ of plastic waste was mixed with bitumen. It was found that the penetration value and ductility decrease with the increasing proportion of plastic waste in bitumen, whereas the softening point increases for every case. Loss on heating, flash \& fire point also been improved with the plastic addition. The performance of Case- 03 (LDPE: $\mathrm{PP}=1: 1)$ is better than others. Minimum penetration value, 11 and maximum softening point, $90^{\circ} \mathrm{C}$, is found for this case, which indicates a $90 \%$ improvement compared to virgin bitumen. Due to the addition of plastic waste, the ductility always gets affected. But overall, a significant improvement in the properties of bitumen is noticeable.
\end{abstract}

Keywords: Waste Management, Plastic Blended Bitumen, LDPE, Polypropylene, Transportation Engineering

\section{Introduction}

Waste management, more specifically solid waste management is the most unestablished area of management round the globe. We as a country, producing tons of waste every day. The appropriate way to dispose the solid waste is in dark to us. It is not only our problem it's a global problem which gradually making this planet worst place to live. Another big global problem is traffic. The amount of traffic on the road is increasing only. To accommodate this enormous number of traffic roads are being constructed more and more [1]. This problem can be reduced to a significant extent by using plastics in road construction. Most of constructed roads over here is bituminous road. In the construction of bituminous pavement, plastics, as well as construction debris, are being used in the form of aggregate and filler materials popularly $[2,20]$. The amount of bitumen can be reduced as well as the strength parameters can be improved by blending plastics with it. This is the technique which has been adopted by the authors in this study.

The main ingredients of the plastics we use in the form of bags, bottles, cup, wrappers and packages are LDPE, PP, PET etc. According to the Bangladesh waste database 2014, Bangladesh has produced 23,688 tons of waste per day and probable generation of waste by 2025 will be 47000 tons per 
day in urban areas [3]. $7.31 \%$ to $8.45 \%$ of this waste is plastic on the basis of the phase of urbanization of that area [3]. These bulk amounts of waste are generally dumped into landfill sites. And the common disposal method of these waste is incineration which is not at all an appropriate method because it emits an enormous amount of $\mathrm{CO}_{2}$ and other toxic gases [3,4]. This process produces $3,622,500.12$ tons of $\mathrm{CO}_{2}$ per annum which is equivalent to $418.98 \mathrm{~kg}$ of $\mathrm{CO}_{2}$ per ton of mixed waste produced [3]. So, there should be some eco-friendly ways to dispose this huge amount of waste plastic to keep the environment safe and clean [2]. This research work focusses on one of that. As the plastic is a non-biodegradable material so, it is intelligent to reuse and recycle rather than dispose off. Using plastic in road construction is not a new concept. Many researchers suggested various approaches to use waste plastics in asphalt road construction. When plastic waste is blended with bitumen mix, plastics also got melted and form an oily film over the aggregate and then mixture is used for surfacing. Here the melted plastics enhances the binding of the aggregates. A comprehensive study on uses of plastics as a coating on aggregate conducted by Vasudevan R. et al shows that the coat not only improves the quality of flexible pavement but also the quality parameters of the aggregates [5]. This study also shows the bigger picture of plastic use. It reduces uses of bitumen by $10 \%$, construction cost by 30,000 Rs. $/ \mathrm{Km}$, and uses of anti-stripping agents on the other hand it increases the strength and performance of the road [5]. Plastic polymer acts as a viscosity modifier of bitumen. The higher viscosity of the plastic mixed bitumen provides a thick coat over the aggregates which modifies the water resistant increasing the adhesion between the asphalt binder and the aggregates [6]. Plastic polymers are not only used as a coat of the aggregate of the asphalt concrete it has also been mixed with pure bitumen to modify the properties of bitumen. Like as thermo plastics thermoset plastics cannot be remolded so it is not suitable to use. A number of researchers has suggested the plastic polymers that have the potential to be used such as, LDPE, PP [7], EVA [8], Crumb rubber [9], recycled polyethylene [10]. A study was conducted by BTF [11] to find the effect of polymer proportion in polymer modified bitumen (PMB) on the ductility, penetration, and softening point. In this study bitumen was partially replaced by polymer content of $8 \%$. The polymer content was consisting of LDPE and PP of 1:3 and 1:1 respectively. It was found that the proportion of LDPE: $\mathrm{PP}=1: 1$ gives the more significant results [11]. Although in some part of the world PMB is being applied in flexible pavement construction but in our country there only some research project has been conducted on this. Islam, M. S. partially replaced the bitumen with LDPE by a percentage of $2.5,5,7.5$, and 10 and the result for penetration, softening point, and viscosity was phenomenal but the ductility was decreased significantly [12]. Hossain did the same job using scrap tire instead of LDPE result was almost same but the viscosity was significantly lower than Islam, M. S. [6]. Panda, et al used the same proportion as Islam and Hossain but polymer used is EVA and result found was better for ductility but not for penetration value of PMB [8]. The characteristics of rubber modified bitumen mixes design were studied by Kumar, et al (2001). In that study they used latex and tire dust as modifier. Study results shows that the rubber imparts a significant increase in Marshall stability, specific gravity, and unit wt. but for the tire dust, the result is not significant and it is also poor with respect to the result for rubber [13]. Panda (1997) studied the performances of reclaimed polyethylene (RPE) modified bitumen. Although the penetration value and the softening point resulted amazing but the ductility was very poor in that study [14]. For Bangladesh, the amount of plastic waste generated like, LDPE and PP is greater than the EVA or rubber. So, the author of this research work chooses to use LDPE and PP as a replacing polymer. From the above review it's clear that a comprehensive study is required to find the effect of the polymer on the properties of bitumen. All the study conducted on this topic just focused on the use of one polymer alone. But in case of our country the waste is no collected separately which results in generation of mixed plastic waste. So, it is more practical to work with the combination on of LDPE \& PP rather than work with them alone. That's why this study focused on the effect of mixed plastic waste blended with bitumen on its properties.

\section{Objectives}

In these modern-days pollution is everywhere. It is none other than us who is responsible for the deterioration of environmental condition of this world [15]. So, the greater goal of the study is to keep the environment clean and safe for the inhabitants of this planet. Keeping this goal ahead the specific aims of this study is to, (i) Justify the potential of the generated plastic waste to serve as a road construction material. (ii) determine the rheological and the engineering properties of bitumen blended with LDPE and PP for different compositions. (iii) Observe the improvement of the properties of virgin bitumen after mixing polymer.

\section{Materials and Methods}

The step-by-step procedure of the laboratory work is illustrated in the flow chart in [Figure 1] bellow.

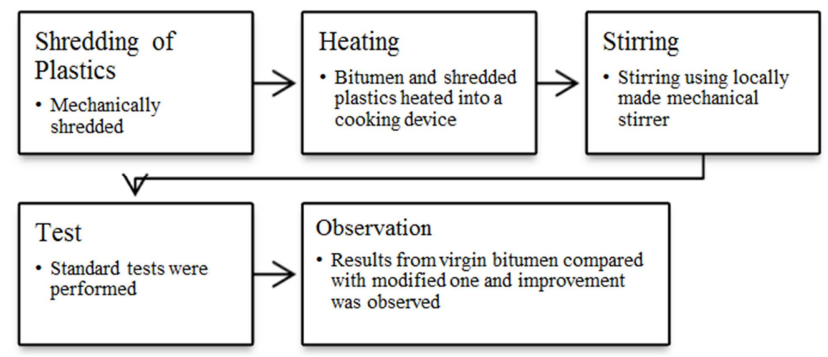

Figure 1. Laboratory work flow.

\subsection{Materials}

The quality of a binder or a asphalt concrete is evaluated by 
its rheological properties [16]. To improve the rheological properties of virgin bitumen (80/100 grade) here in this study the authors used LDPE (Low-density polyethylene) and $\mathrm{PP}$ (Polypropylene) as the bitumen modifier. The proportion at which this polymer is used is represented in the Table 1.

Table 1. Proportion of polymer to modify the bitumen.

\begin{tabular}{llll}
\hline $\begin{array}{l}\text { Bitumen Content } \\
(\%)\end{array}$ & $\begin{array}{l}\text { LDPE } \\
(\%)\end{array}$ & $\begin{array}{l}\text { LDPE: PP=1:1 } \\
(\%)\end{array}$ & $\begin{array}{l}\text { LDPE: PP=1:1 } \\
(\%)\end{array}$ \\
\hline 100 (Virgin) & 0 & 0 & 0 \\
97 & 3 & 3 & 3 \\
94 & 6 & 6 & 6 \\
91 & 9 & 9 & 9 \\
88 & 12 & 12 & 12 \\
85 & 15 & 15 & 15 \\
\hline
\end{tabular}

\subsection{Blending Polymer}

Shredding of the plastics to small size was done first. Then it was blended with binder. There are two types of blending methods to blend the plastic polymer with the bitumen binder [6]. One of them is dry process and another is wet (Cooking method). Here for this study wet process was adopted to blend the plastic polymers with bitumen. Blending was done by hand made blender. A Stirrer with shear Blade was made up with hand drill machine to blend the polymer properly. Then the bitumen and shredded plastics were poured into the cooking device after that the heating and stirring performed simultaneously until they mix properly.

\subsection{Testing the Properties of the Blended Bitumen}

To evaluate the improvement of the properties the following tests were performed for PMB (Polymer Modified Bitumen), Penetration value, Softening point, Ductility, Loss on Heat, Flash Point, and Fire point. The tests were performed following the AASHTO standards which are mentioned in Table 2 .

Table 2. Standards for the test of Bitumen.

\begin{tabular}{lllllll}
\hline Tests & Penetration & Softening point & Ductility & Loss on heat & Flash point \\
\hline Standards & AASHTO T49-93 & AASHTO T53-92 & AASHTO T51-93 & AASHTO T47- 83 & AASHTO T 48 - 91 & AASHTO T 48 - 91 \\
\hline
\end{tabular}

\section{Results and Discussions}

To assess the quality improvement compared to the reference binder, Virgin bitumen with polymer modified bitumen (PMB), Penetration, softening point, Ductility, Loss on heating, and Flash \& Fire point tests were carried out on both virgin bitumen (VB) and polymer modified bitumen (PMB) of proportion stated above. In this section the test results are demonstrated in graphical form.

\subsection{Penetration Value Test}

Penetration value is measure of consistency of solid and semisolid matters. Specially for bitumen the penetration value test is used to classify it into standard consistency grades. Penetration value is significant for bleeding problem in hot weather. So, higher value is expected. As the age of bitumen increases the penetration value decreases and form crack in bituminous pavements. But one thing should be remembered that since the grade of bitumen has nothing to do with quality of bitumen so, the penetration value do not reflect the quality of binder it's just a classifying parameter. The laboratory test results for this study has been presented in [Figure 2 (a)]. The test results depict that the penetration value decreases with increment of the plastic content with respect to virgin bitumen regardless of the types of polymer. In depth, it also clarifies that the sequence of rate of reduction of penetration is $\mathrm{LDPE}<(\mathrm{LDPE}: \mathrm{PP}=3: 1)<$ (LDPE: $\mathrm{PP}=1: 1$ ). That means, as the amount of PP (Polypropylene) increases the penetration value decreases. The rate of reduction of penetration value decreases with the increment of polymer percentage. This result justifies the significance of use of mixed plastic waste as a bitumen modifier.

[Figure $2(b-d)$ ] depicts the distribution of penetration value around the mean value. It is clearly visible from all of the three figure that the $67 \%$ of penetration value is within mean $+1 \sigma$ (Standard Deviation) and $100 \%$ value lies within mean $+2 \sigma$ (Standard Deviation) which is a characteristic of a normal distribution. So, here we can conclude that the penetration value obtained from the experiment is normally distributed around the mean penetration value.
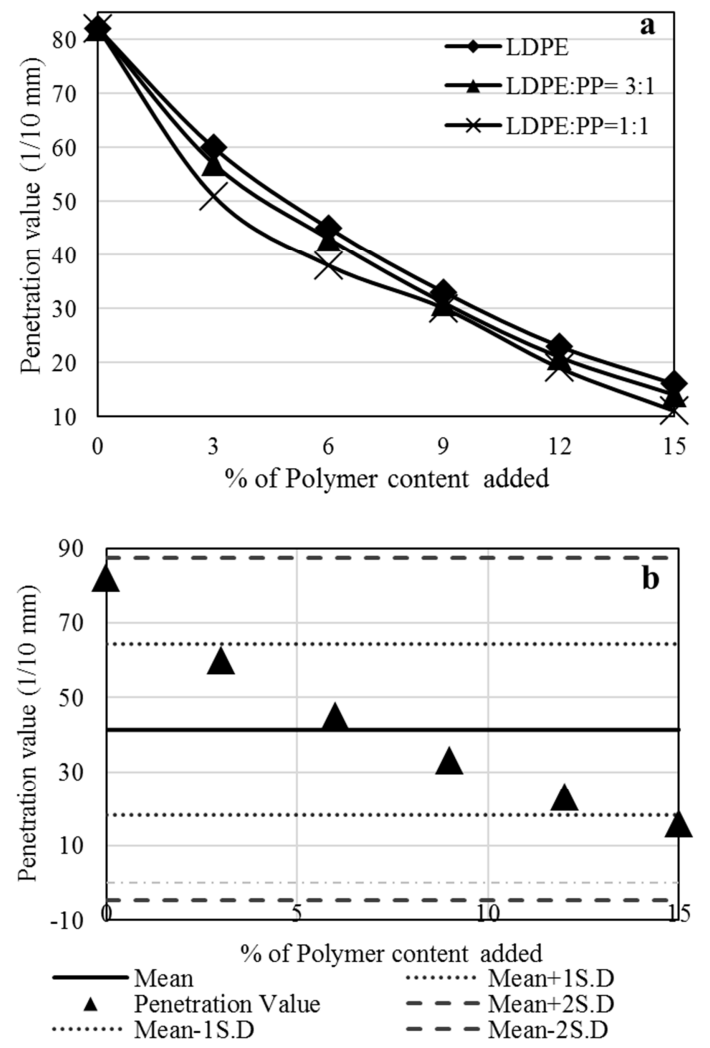

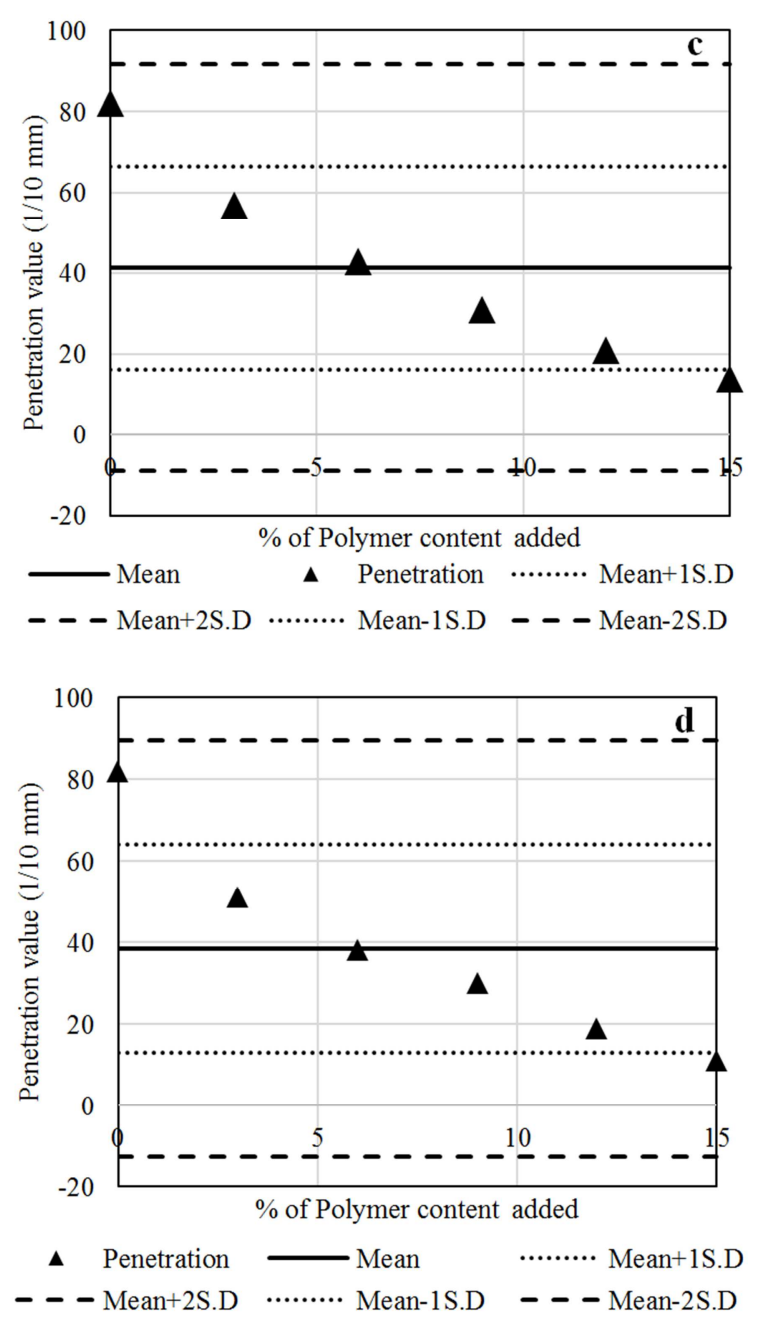

Figure 2. (a) Variation of Penetration value with the percentage of Polymer content added to bitumen (b) Distribution of penetration value around the mean for $L D P E(c)$ Distribution of penetration value around the mean for LDPE: $P P=3: 1$ (d) Distribution of penetration value around the mean for LDPE: $P P=1: 1$.

\subsection{Softening Point Test}

Softening point is defined as the measure of temperature at which binder material changes it's state from semi solid to liquid under the weight of a standard steel ball [17]. It represents the susceptibility of the binder to temperature. Due to the low softening point bleed and segregation takes place in hot weather. For the tropical countries like Bangladesh the softening point should be less to counter the distresses of pavements. The test results of this study are illustrated in [Figure 3] which depicts the same trend as penetration value test. Here also the softening point increases with the increment of polymer content regardless of polymer type. Increment rate is high up to $9 \%$ of polymer the it gets slow down a bit. Here the result for LDPE: $\mathrm{PP}=1: 1$ is remarkably high. For LDPE: $\mathrm{PP}=1: 1$ the softening point increased by 1.91 times of virgin bitumen whereas the result for LDPE: $\mathrm{PP}=3: 1$ and LDPE are also phenomenal. Here the highest value of softening point of PMD found is $90^{\circ} \mathrm{C}$ whereas it's for VB (Virgin bitumen) is $47^{\circ} \mathrm{C}$. The result clarifies that the use of mixed plastic polymer results to a satisfactory softening point.

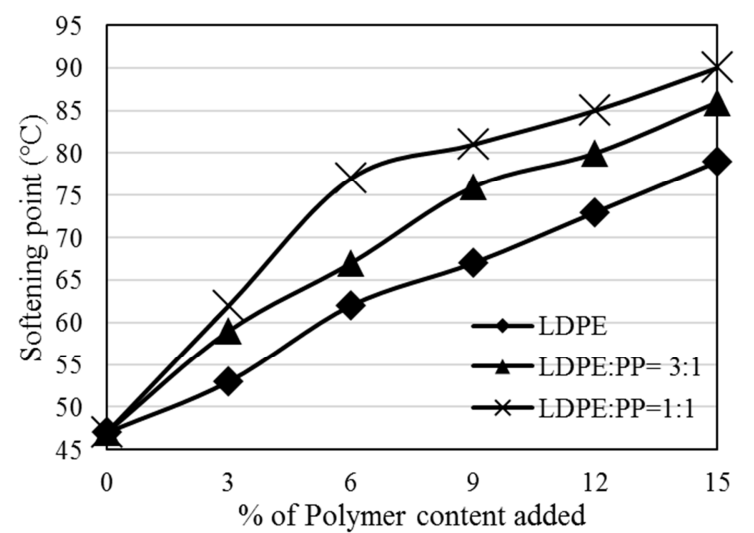

Figure 3. Variation of Softening point with the percentage of Polymer content added to bitumen.

\subsection{Ductility}

Ductility is a measure of the length beyond which a bitumen briquet specimen can be elongated by pulling to end apart at a specific speed and temperature. It represents the elasticity of a bitumen specimen. Less ductility may result in cracking of pavement. But the bitumen with high ductility is not necessarily of good quality bitumen. [Figure 4] depicts that the ductility decreases with the increase of polymer content at a high rate up to $3 \%$ of polymer content. Higher decrease in ductility may make the bitumen unfit for use. So, the selection of optimum polymer content to modify bitumen should be determined on the basis of the result of ductility. From the result it is clear that for $\mathrm{LDPE}: \mathrm{PP}=1: 1$ the optimum polymer content could be $9 \%$ but for LDPE \& LDPE: $P P=3: 1$ it should not be more than $6 \%$. Although the increment of polymer content reduces the ductility but simultaneously it increases the elasticity (flow) of the binder.

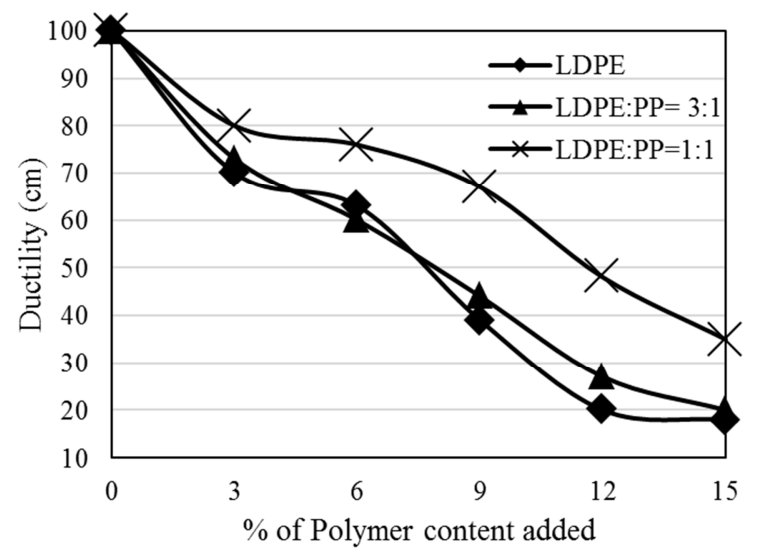

Figure 4. Variation of Ductility with the percentage of Polymer content added to bitumen.

\subsection{Loss on Heating}

The measure of losses of volatile materials present in bitumen is termed as loss on heating of bitumen. Loss of heating for bitumen is a very small figure in laboratory 
condition so, to measure the loss accurately there must be a very precise and sensitive balance. Lack of precise balance and intensive observation this result some error. The results in [Figure 5] portrays that the Losses on heating decrease with the addition of polymer content. But the change is not uniform.

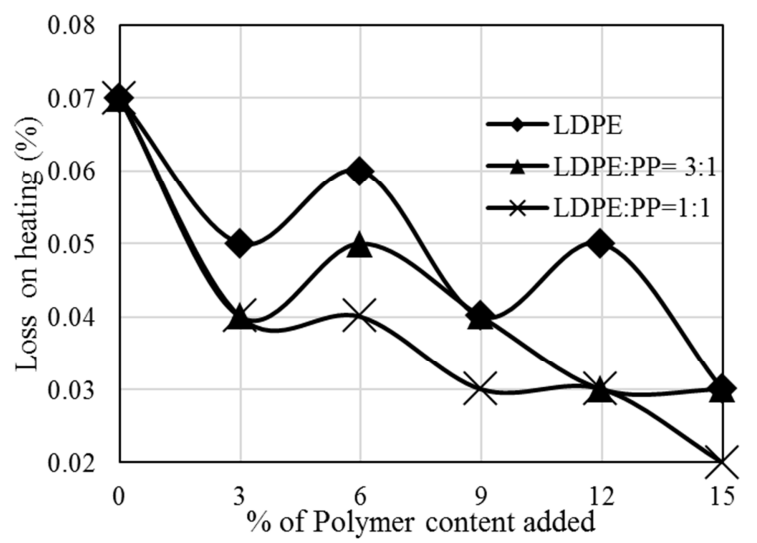

Figure 5. Variation of Loss on heating with the percentage of Polymer content added to bitumen.

\subsection{Flash and Fire Point}

Flashing and fire point test for bitumen is a safety test for bitumen to work with. Higher the flash \& fire point higher the safety of the bitumen during heating. Here we can see in the [Figure 6] that the flash and fire point increases with the increment of polymer content up to a certain level then decreases. Optimum level of polymer content is around $6 \%$.

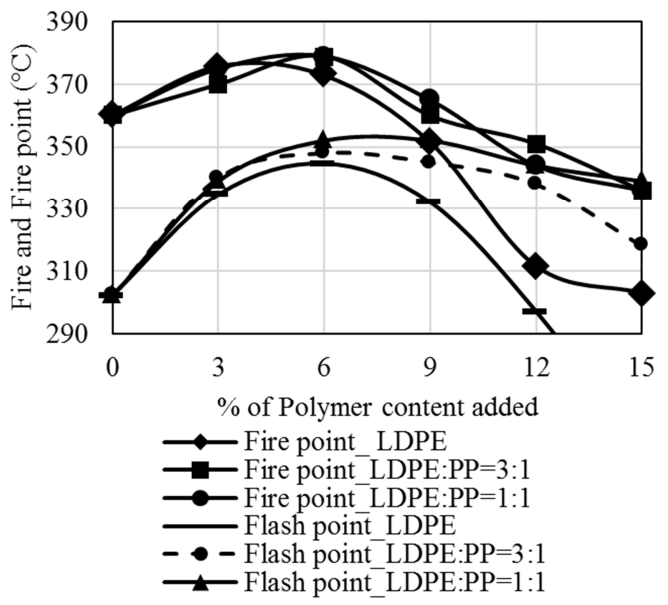

Figure 6. Variation of Flash \& Fire point with the percentage of Polymer content added to bitumen.

\subsection{Potential of Plastic Use}

A study on import of plastic polymer in Bangladesh was carried out at BUET. Summary of that study is presented in Table 3. Its shows that the volume of import of plastic polymer is increasing every year so it is obvious that the corresponding solid wastes derived from these imported polymers is also increasing. A study carried out by waste concern Bangladesh shows that by 2025 will be 47000 ton per day of which around $10 \%$ will be plastic waste [3]. Per capita waste generation will be $0.6 \mathrm{Kg}$ /day according to Waste database 2014 [3] according to Hoornweg \& Bhada-Tata [18] it will be $0.75 \mathrm{Kg}$ /day. These huge amounts of plastic waste will be a curse for our country. Only the incineration will not be sufficient for this huge amount of waste. So, use of this non-biodegradable curse can be converted into resource by using it in road construction. The worth of its use is justified in this study.

Table 3. Import of LDPE and PP polymers in Bangladesh [19].

\begin{tabular}{llllll}
\hline \multicolumn{1}{l}{ Year } & $\mathbf{8 8 - 8 9}$ & $\mathbf{9 7 - 9 8}$ & $\mathbf{2 0 0 5 - 0 6}$ & $\mathbf{2 0 0 6 - 0 7}$ \\
\hline \multicolumn{2}{l}{ Total Import (ton) } & 9,989 & 86,318 & $2,73,874$ & $2,88,646$ \\
PE & In Ton & 3,046 & 30,527 & 72,056 & 82,928 \\
Import & In (\%) & 30.49 & 35.37 & 26.31 & 28.73 \\
PP & In Ton & 2,105 & 12,835 & 68,742 & 85,497 \\
Import & In (\%) & 21.07 & 14.87 & 25.10 & 29.62 \\
\hline
\end{tabular}

\section{Conclusion}

Plastic waste has been a proven curse for the planet earth. The processes that are usually used to dispose it off are not suitable to the environment so the only way to get rid of this problem is either reuse or recycle. One of the emerging recycle is use in road construction. This study which focused on the potential and the effect of plastic waste on rheological and the engineering properties of bitumen can be concluded as follows,

Blending polymer with bitumen improves Penetration value, softening point, Ductility, Loss on heating, and Flash \& Fire point test but reduces the ductility remarkably.

LDPE \& PP polymer waste mixed together with bitumen results more phenomenal than LDPE alone for all properties.

LDPE: $\mathrm{PP}=1: 1$ combination gives the best result for all of the tests, Penetration value, Softening point, Ductility, Loss on heating, and Flash \& Fire point test. Results for LDPE and LDPE: $\mathrm{PP}=1: 1$ is also sufficiently satisfying.

Optimum result for all test found at $6 \%$ to $9 \%$ beyond that the ductility properties get lowered very critically.

$6 \%$ to $9 \%$ of (LDPE: $\mathrm{PP}=1: 1$ ) can be used for the modification of bitumen with plastic waste for best result.

Use of PMB reduces losses and enhances the construction safety by increasing flash and fire point.

Bangladesh generates a sufficient amount of waste to use it conveniently in road construction.

\section{References}

[1] Islam, M. M., Islam, M. S., Rahman, F. I. (2019). "A Brief Study on Capacity Loss at Major Rajshahi City Roads, Bangladesh". In: Proceedings of International Conference on Planning, Architecture and Civil Engineering. Rajshahi, Bangladesh, pp 1-6.

[2] Harun-or-rashid, G, M \& Islam, M. M. (2020) A Review Paper on: Effect of Different Types of Filler Materials on Marshall Characteristics of Bitumen Hot Mix. 9:40-46. https://doi.org/10.11648/j.ijmsa.20200903.11.

[3] Enayetullah I, Sinha AHMM, Lehtonen I (2014) Bangladesh Waste Database 2014. 1-19. 
[4] Shantosh kumar Garg (1999) Environmental engineering, vol. II. Khanna Publishers, Delhi.

[5] Vasudevan R, Ramalinga Chandra Sekar A, Sundarakannan B, Velkennedy R (2012) A technique to dispose waste plastics in an ecofriendly way - Application in construction of flexible pavements. Constr Build Mater 28: 311-320. https://doi.org/10.1016/j.conbuildmat.2011.08.031.

[6] M. A. Hossain (2006) a Study on the Rheological Properties of Polymer Modified Bituminous Binder and Mixes.

[7] Zoorab SE SL (2000) Laboratory design and performance of improved bituminous composites utilizing recycled plastics packaging waste. Present Technol Watch Innov Constr Ind Palais 203-9.

[8] Panda M, Mazumdar M (1999) Engineering properties of eva-modified bitumen binder for paving mixes. J Mater Civ Eng 11:131-137.

https://doi.org/10.1061/(ASCE)0899-1561(1999)11:2(131).

[9] Hossain M, Swartz S, Hoque E (1999) Fracture and tensile characteristics of asphalt-rubber concrete. J Mater Civ Eng 11:287-294.

https://doi.org/10.1061/(ASCE)0899-1561(1999)11:4(287).

[10] Murphy M, O'Mahony M, Lycett C, Jamieson I (2001) Recycled polymers for use as bitumen modifiers. J Mater Civ Eng 13:306-315. https://doi.org/10.1061/(ASCE)0899-1561(2001)13:4(306).

[11] (2008) Plastic Recycling for Environmental and Transport Improvements. a Feasibility Study by Bangladesh Transp Found.
[12] Islam MS (2003) A Study on the Prospects of Using Polymers in Bituminous Binder and Mixes. M Eng Proj Dep Civ Eng Bangladesh Univ Eng Technol.

[13] Kumar, M. M., and Kumar, M. S. " A (2001) Study on Rubberized Bituminous Mixes. J Indian Highw.

[14] Panda, M., and Mazumder M (1997) Development and evaluation of a bituminous paving binder containing reclaimed polyethylene. Indian Highw.

[15] G. M. H. Rashid, M. M. Islam MSI\& MNH (2019) A Brief Study On Water Quality Liable for Contaminating the River Padma, Rajshahi. Proc Int Conf Planning, Archit Civ Eng 7-9.

[16] Abul Kashem M (2012) Use of Waste Plastic Blended Bitumen for Road Construction and Maintenance. MSc thesis, BANGLADESH Univ Eng Technol 20.

[17] AASHTO T53-92 Standard test method for determination of softening point of bitumen by Ring and Ball Apparatus.

[18] Hoornweg, D \& Bhada-Tata P (2012) What a Waste: A Global Review of Solid Waste Management. Urban Dev Local Gov Unit, World Bank, Washington, DC, USA.

[19] (2008) Use of Waste Plastics with Bitumen for Road Construction. Bangladesh, Dhaka by Bangladesh Univ Eng Technol.

[20] Shirin, M., S., Islam, M. M. \& Kumruzzaman, M.(2020). Stabilization of Coal Mine Waste and Its Practical Application as a Road Subgrade. American Journal of Traffic and Transportation Engineering. Vol. 5, No. 5, pp. 51-56. doi: 10.11648/j.ajtte.20200505.11. 